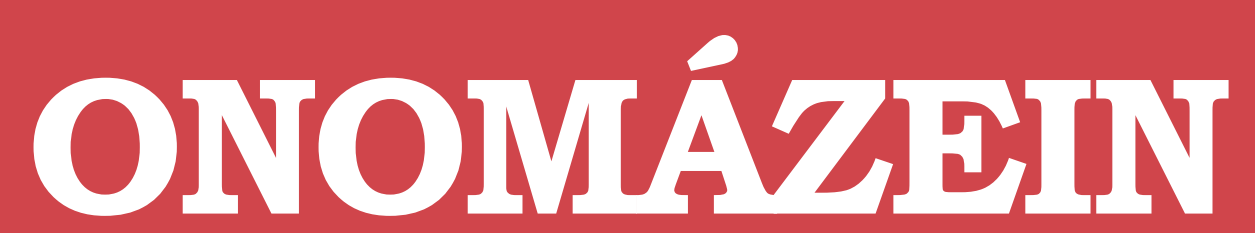

Revista semestral de lingüística, filología y traducción
PONTIFICIA UNIVERSIDAD

\title{
El testamento como género discursivo en documentación peninsular (de la Edad Media al siglo XVIII)*
}

Testament as a discursive genre in peninsular documentation (from the Middle Ages to the eighteenth century).

\section{Cristina Tabernero}

Universidad de Navarra

españa

\section{(c) $(i)$}

Cristina Tabernero: Departamento de Filología, Facultad de Filosofía y Letras, Universidad de Navarra, España. | Correo electrónico: ctabernero@unav.es 


\section{Resumen}

Se analiza en este artículo la evolución del discurso testamentario a partir del cotejo de ciento cincuenta documentos de diferentes sintopías, que se contrastan asimismo con las indicaciones de los manuales de escribientes de las épocas estudiadas. Los resultados de este trabajo aportan nuevos datos sobre la variación cro- nológica y geográfica de este tipo textual y sobre los usos lingüísticos y discursivos que lo caracterizan, y demuestran la relevancia del escribano, de las condiciones de enunciación y del contexto histórico en un género comúnmente considerado como prefijado e inmóvil.

Palabras clave: variación; testamento; discurso; escribano; enunciación; contexto histórico.

\section{Abstract}

This article analizes the testamentary discourse evolution on the basis of the comparison of a hundred and fifty documents of different syntopies. These documents are also contrasted with the guidelines from the copyists' handbooks of the studied periods. This work's results cast new light on the chronological and geographic variation of this textual type as well as on the linguistic and discoursive uses which characterize it. Furthermore, these outcomes show the relevance of the copyist, as well as that of the enunciation conditions and the historical context in a genre which is commonly believed to be immobile.

Keywords: variation; testament; discourse; copyist; enunciation; historical context.

* Este trabajo forma parte de los resultados del proyecto HAR2012-31536, Discurso y poder, lengua y autoridad en el mundo hispánico (siglos XVI-XVII), subvencionado por el Ministerio de Economía y Competitividad. 


\section{El estudio de la tipología documental testamentaria}

Han sido sobre todo los investigadores de la historia y del derecho quienes se han interesado por la tipología documental testamentaria; los primeros, en su intento de conformar una historia de las mentalidades, considerando el testamento una de sus mejores vías de investigación; como modo de establecer la trayectoria de una tradición legal, los segundos.

La concepción actual del testamento como "justa declaración de nuestra voluntad sobre lo que cada uno quiere que se haga después de su muerte" (Lalinde, 1998: 818) no coincide con la de épocas pasadas, en las que la escritura de estos textos representaba una preparación para ese momento último, en la línea de las artes del bien morir, que proliferaron a partir del Concilio de Trento.

El componente religioso de esta práctica se extenderá desde los siglos medios hasta la centuria dieciochesca y solo más adelante irá predominando el sentido propiamente jurídico, que hará desaparecer, al menos como elementos de presencia obligada, invocaciones y mandas pías (Martínez Gil, 1993: 1068).

Históricamente anclado en la sociedad romana, que lo empleaba como medio para la transmisión patrimonial, el testamento sufre una época de declive durante la Alta Edad Media a causa de la entrada de las costumbres germánicas, si bien la recuperación del derecho romano a partir del siglo XII provocará la vuelta al uso antiguo y, en consecuencia, un aumento cuantitativo considerable - se ha hablado incluso de "renacimiento del testamento” (Chiffoleau, 2011: 35; Campo,
2011: 9) - con la consiguiente "democratización" de esta práctica (Campo, 2011: 10).

Esta continuidad jurídica se traduce, asimismo, en la invariabilidad estructural que el documento testamentario presenta desde su nacimiento, cualquiera que sea la lengua de su redacción - latina o romance-, y que encontramos expresada ya en las Partidas (III, tít. XVIII, ley CIII) y en el Espéculo (IV, tít. XII, ley XLIIII) alfonsíes. Es justamente esta característica la que ha cuestionado, tanto desde el punto de vista histórico como lingüístico, el interés del estudio de unos textos predeterminados, que no dejan lugar a la intervención del individuo, lo que no permite comprobar — según se ha dicho- el devenir de los hombres ni de las lenguas. A apoyar esta idea vendrían, en principio, los numerosos manuales para escribanos que, con un objetivo similar al del "arte notarial" de la Edad Media, circularon por España, sobre todo a partir de los siglos XVI y XVII; en ellos se indicaban las partes y fórmulas que debían estar presentes en los distintos tipos documentales, anulando, en principio, la creatividad de la emisión. Aparece entonces como elemento de consideración nuclear desde todas las perspectivas indicadas la figura del escribano, que, conocedor de los formularios, tomará también sus propias decisiones en la redacción del documento (Lorenzo, 1989: 33; Rodrigo, 2002: 73).

Sin embargo, lejos de este supuesto desinterés, juristas, historiadores y lingüistas han abordado con éxito el análisis de la tipología testamental. En concreto, desde el estudio histórico de la lengua, se ha descrito la estructura y usos lingüísticos de diferentes testamentos ${ }^{1}$ y se ha afirmado, al igual que en otras disciplinas, el valor de aquellos como reflejo de las sociedades

1 Véase los trabajos de Díez de Revenga e Igualada (1997) y Heredia (2003). En Navarro (2012) se aborda asimismo esta tipología textual a partir del análisis de las construcciones pasivas y relativas en relación con los rasgos propios de la inmediatez comunicativa y el contacto de lenguas. Esta misma autora (Navarro, 2015: 87-165) ofrece un estudio más amplio de la tipología textual testamentaria americana a partir del estudio de la documentación cuzqueña (siglo XVI) de Pedro Quispe, primer notario indígena También a las estructuras pasivas de los testamentos se dedica el trabajo de Sainz (2011). Por su parte, Medina López (1997) atiende al análisis de los rasgos fónicos de la documentación testamentaria canaria que emplea como corpus; Kordic (2005: 19-29), en el prólogo a la edición de testamentos coloniales chilenos, describe los principales rasgos lingüísticos de estos. 
en las que se inscriben, núcleos de convivencia entre tradición y cambio. Así pues, siendo numerosos ya los trabajos que desde ángulos distintos nos van permitiendo conocer esta tipología documental, es este el momento idóneo, creo, para abordar un análisis comparativo entre estudios y documentos testamentarios de diferentes sintopías.

\section{Corpus de estudio}

Con esta finalidad se han revisado las siguientes fuentes: trece testamentos recogidos en el CODEA, fechados entre el siglo XIII y el siglo XVI2; sesenta y seis zaragozanos contenidos en el Libro de testamentos de 1387-1407 del notario Vicente de Rodilla (Campo, 2011); veinte textos altoaragoneses del siglo XVII (Rapún, 2001-2002); los treinta y nueve albaceteños fechados entre 1588 y 1600, publicados por P. J. García Moratalla (1999); tres testamentos del norte de Navarra, dos del siglo XVII - todavía sin editar - y uno del XVIII (Tabernero, en prensa), pertenecientes a un archivo particular, y fechados en 1633, 1635 y 1762; los ocho textos del siglo XVIII que transcribe $M$. Reder (1986) en su estudio sobre testamentos malagueños y una escritura testamentaria de esta última centuria, que recogen Gómez Seibane y Ramírez
Luengo (2007: 111-122) en sus documentos de Bilbao; además, claro está, de los resultados expuestos en diferentes trabajos sobre la lengua testamentaria ${ }^{3}$

Por otro lado, según lo apuntado en las líneas anteriores, resulta inexcusable la consulta de los manuales de escribientes, cuyo estudio ha permitido establecer, desde la Edad Moderna hasta el siglo XVIII, una evolución clara en el desarrollo de la literatura notarial de esta época, de modo que se ha distinguido entre la primera mitad del siglo $\mathrm{XVI}^{4}$, continuadora del período bajomedieval, la segunda mitad del XVI y todo el siglo XVII ${ }^{5}$, finalmente, el siglo XVIII, en el que se observa una simplificación y racionalización de los usos notariales (Bono y Huerta, 1980: 287-318; Mártir, 2011: 27) ${ }^{6}$.

Esta literatura notarial se desarrolla desde fechas tempranas en Castilla, Aragón, Valencia y Cataluña (Bono y Huerta, 1980), sin que se conozca noticia alguna de otros reinos como Navarra (Bono y Huerta, 1980; García-Granero, 1980).

Así pues, se cotejan en estas páginas las fórmulas de los distintos testamentos con las que señalaban los autores de estos manuales de escribientes. Se ha tenido en cuenta a tal efecto el estudio de M. J. Mártir (2011) sobre los testamentos en los formularios castellanos del siglo XVI, la relación de manuales de escribientes que se ana-

2 Ofrezco a continuación la referencia de los trece documentos del CODEA, base de datos elaborada por el grupo de investigación GITHE, según el esquema fecha, lugar y número de identificación en el corpus, que se han tenido en cuenta en este estudio: Zaragoza, 1227 ( $n^{\circ} 1223$ ); Navarra, 1227 ( $\left.n^{\circ} 1399\right) ;$ Rubielos de Mora (Teruel), 1277 ( $n^{\circ} 766$ ); Rubielos de Mora (Teruel), 1341 ( $n^{\circ}$ 602); Zaragoza, ca. 1363 ( $n^{\circ}$ 755); Rubielos de Mora (Teruel), 1378 ( $n^{\circ} 767$ ); Astorga (León), 1407 ( $n^{\circ} 1246$ ); Sangüesa (Navarra), 1417 (nº 993); Hita (Guadalajara), 1481, (nº 173); Calatayud, 1506, (nº 838); Sarrión (Teruel), 1522 (nº 757); Zaragoza, 1529 (n 798); Guadalajara, 1598 ( $n^{\circ}$ 195). Se han seleccionado los documentos que responden a la tipología testamento.

3 Véase, principalmente, Díez de Revenga e Igualada (1997) y Heredia (2003). El primero de estos trabajos se ocupa de veinte testamentos murcianos de los siglos XV y XVI y el segundo abarca desde la Edad Media hasta la época actual en la siguiente proporción: cinco documentos castellanos fechados entre 1197 y 1272; cinco documentos albaceteños del siglo XVI (1588-1592) de los estudiados por J. García Moratalla (1999) y cinco textos del siglo XX.

4 Destacan en este período los manuales del Relator — todavía de finales del siglo XV—, el de Juan de Medina, el de Hernando Díaz de Valdepeñas y el de Roque de Huerta (Mártir, 2011).

5 "Desde la segunda mitad del siglo XVI se inicia en la disciplina notarial un giro transcendente: se abandona la concepción del simple formulario, desprovisto de aclaraciones legales o doctrinales, y se aborda la empresa de crear verdaderos tratados de Derecho notarial (tal como habían sido los clásicos del Ars notarie)" (Bono y Huerta, 1980: 294). Encontramos en esta época los formularios de Diego de Ribera, Gabriel de Monterroso y Alvarado Lorenzo de Niebla, Bartolomé de Carvajal y Francisco González de Torneo.

6 Para un estudio exhaustivo de estos manuales del siglo XVI, véase Mártir (2011). En las páginas de este trabajo se da cuenta también de los formularios anteriores y posteriores a la centuria del quinientos (véase especialmente páginas introductorias). 
liza en esta misma monografía y los formularios notariales aragoneses de los siglos XV (Formulario notarial del Archivo Municipal de Barbastro) y XVI (Formulario notarial zaragozano de la primera mitad del siglo XVI).

Pretendo, por tanto, que mi trabajo se sume a la caracterización de la tipología testamental realizada hasta ahora y, de acuerdo con quienes buscan "una teoría de clasificación textual que considere los rasgos lingüísticos y su relación con las condiciones de enunciación, que contemple los discursos como objetos sociohistóricos en los que se puede seguir la relación entre los cambios en la historia social y los cambios en los tipos de discursos" (Pons, 2008: 221)7, esbozaré en estas páginas los rasgos definidores y cambios de la tipología testamental a partir del estudio de documentos de épocas diferentes y una misma configuración, teniendo en cuenta, además del producto textual, las condiciones de enunciación en las que se incluyen las características del emisor y el contexto ideológico y sociohistórico.

\section{Estructura textual y usos lingüísticos en el discurso testamentario}

Las escrituras testamentarias consideradas siguen la estructura al uso de esta práctica jurídica, esto es, aquella que se ha descrito como propia de este tipo de texto, sin apenas solución de continuidad desde la Edad Media hasta la actualidad, con pequeñas modificaciones que afectan el lugar que ocupa la validación notarial y a las personas gramaticales empleadas en la redacción; la primera persona como voz del testador y del escribano en la tradición medieval y áurea frente a la tercera de la reproducción indirecta y la primera del notario en los testamentos actuales (Heredia, 2002: 176) ${ }^{8}$.

Coincidiendo con lo descrito en otras ocasiones (Peñafiel, 1987; García Moratalla, 1999; Heredia, 2003: 163 y 171), el documento testamentario, en cualquiera de las épocas contempladas en este estudio, se estructura según el esquema de protocolo inicial, que en los siglos clásicos contiene la invocación, la notificación y la intitulación; el cuerpo del testamento, que recoge las cláusulas expositivas y dispositivas; y el protocolo final, que en los siglos XVI9, XVII y XVIII incluye la datación tópica y cronológica junto a la validación.

\subsection{El protocolo inicial o cabeza del tes- tamento}

\subsubsection{La invocación}

En nuestro corpus documental la invocación se expresa en la mayoría de las ocasiones con la fórmula heredada de la tradición latina (Codoñer, 1972, y Benavides, 2000) "In dei Nomine amen”, “En el nombre de nuestro señor”, la más comúnmente empleada en esta tipología textual (Peñafiel, 1987: 49-52).

El protocolo se inicia en muchos de los casos de cualquiera de las cronologías analizadas con la fórmula "Sepan quantos", que comenzaría a usarse en el siglo X y se emplearía como modelo de escritura en las Partidas alfonsíes y en los manuales de escribientes de los siglos XVI y XVII (Mártir, 2011: 212-215). A esta primera construcción se añade, también de forma generalizada, la calificación jurídica — "Sepan quantos esta presente carta de testamento y vitima voluntad y dispossicion de bienes bieren"-, que, sin em-

7 Esta “teoría de clasificación textual” viene representada en la lingüística más reciente por los estudios sobre tradiciones discursivas.

8 En los estudios consultados es unánime la referencia a la invariabilidad de la estructura testamentaria.

9 Para la estructura de los testamentos de los siglos XV y XVI, véase Díez de Revenga e Igualada (1997: 39-46). Asimismo, M. L. Rodrigo (2002) examina los cambios formularios de distintas partes de los testamentos como reveladores de los cambios sociales y culturales. 
bargo, desaparecerá de los tratados, en un ejercicio de depuración estilística, en la segunda mitad del siglo XVI (Mártir, 2011: 215).

No obstante, se constatan diferentes testimonios de variación sobre el uso común, como sucede en los textos murcianos del siglo XVI, que registran la fórmula "sea notorio" - "sea notorio a los que la presente carta de testamento vieren"-, continuadora, al igual que la anterior, de la tradición medieval, y el más aislado "notorio y manifiesto sea", del testamento navarro del XVIII - "Notorio y manifiesto sea a cuantos el presente instrumento de testamento y ultima disposicion de vienes bieren et oyeren" (Villava, 1762) - , presente también en otras tipologías documentales, como la provisión de Enrique IV (CODEA, Segovia, 1471), una capitulación del Señorío de Vizcaya (CORDE, 1539) o un contrato de venta zaragozano (CORDE, 1519-1547), localizadas casi en su totalidad en documentación aragonesa y castellana de los siglos XVI y XVII, si atendemos a los datos ofrecidos por el banco de datos académico.

Frente al carácter puntual de estos testimonios, son numerosas en los documentos anteriores a 1700 las notificaciones que comienzan con la fórmula manifiesto sea/sia o sia manifiesto ${ }^{10}$, a distancia todavía durante los siglos medios y modernos de la más común con el verbo saber ("Sepan quantos esta carta vieren..."). El cambio, por tanto, se produce en primera instancia de los tradicionales saber ("Sepan todos") o conocer ("conoçida/conoçuda cosa sea") de la documen- tación medieval, como fórmula de notificación pública ${ }^{11}$ y manifiesto ('descubierto, patente y claro') o notorio ('público y sabido por todos'), que modifican el interés hacia la publicidad del hecho y no solo al conocimiento. Cabe señalar, por otro lado, el reparto geográfico entre las fórmulas manifiesto sea o sea manifiesto en Aragón ${ }^{12}$ para documentos de contenido diverso redactados entre 1301 y 1574 y sea notorio en testamentos castellanos de finales del siglo XVI y principios del XVII ${ }^{13}$.

Posteriormente, la presencia de manifiesto en binomios léxicos ${ }^{14}$ junto a notorio, que destaca el mismo rasgo semántico que el anterior, concluye con la consolidación en el siglo XVIII de notorio y manifiesto como fórmula de notificación, característica también de otras tipologías documentales, en las que pudo extenderse con anterioridad a esta de los testamentos ${ }^{15}$ y previamente, además, en el español de la zona septentrional.

\subsubsection{Intitulación}

Las fórmulas de intitulación, que comienzan a tener este carácter retórico desde los scriptoria de la Alta Edad Media (Laffon, 1989: 143-145; Mártir, 2011: 215), podían ser más o menos extensas en virtud de los datos que se proporcionaran sobre el testador; el nombre y vecindad de las fórmulas más breves se acompañaría en otras ocasiones del estado civil, profesión o de la indicación de

10 El orden verbo + adjetivo (sea o sia manifiesto) resulta más duradero en el tiempo que la fórmula adjetivo+ verbo (manifiesto sea o sia).

11 Como señala M. J. Mártir (2011: 214-215), "[s]u presencia se fundamenta en la idea de que al ser los contratos una ley entre partes, deben promulgarse para que lleguen a conocimiento de todos, es una llamada al destinatario o destinatarios de que a continuación se expondrán los contenidos del documento".

12 De los cuarenta y nueve testimonios de las fórmulas de notificación sea manifiesto o manifiesto sea en los textos del CODEA, 47 se reparten entre Zaragoza (24), Huesca (14) y Teruel (9); solo dos de ellos se emiten en Salamanca.

13 La revisión de testamentos de Albacete entre 1588 y 1600, publicados en García Moratalla (1999), arroja un resultado a favor de la fórmula de notificación "sea notorio a todos" frente a "sepan... vieren".

14 Se entiende por tales la coordinación de dos palabras en el discurso.

15 Por ejemplo, comienza de este modo un documento de "coto y ordenanza" del Concejo de Beinza-Labayen (Navarra) del 20 de julio de 1620: "Notorio y manifiesto sea a quantos la presente escritura de coto y ordenanza bieren y leyeren". También de 1620 es, sin embargo, el testamento de Guillaume Brugieres, redactado en Valladolid: "Notorio y manifiesto sea a todos cuantos vieren esta escritura publica de testamento". 
los padres.

La estructura de los testamentos incluye a continuación, como prueba de validez de la carta testamentaria, la buena salud mental del testador, la única que lo capacita para testar, pudiendo estar resentida, sin embargo, la salud física ${ }^{16}$.

A este respecto, los distintos estudios sobre cartas de testamento se refieren a diferentes fórmulas que se articulan léxicamente entre los siglos de la Edad Media y Moderna en torno al seso, juicio, entendimiento y memoria, que pueden calificarse como buenos, enteros o cumplidos. Los documentos medievales, por ejemplo, se dividen entre variantes ${ }^{17}$ como "plenerament in mea memoria" (1233, Zaragoza), "in sensu meo et in mea bona memoria” (1227, Navarra), "en mi buen seso, éntrega memoria e firme palavra" (1277, Teruel), "en mi buen seso, éntrega memoria” (1341, Teruel), "en mi buen seso, e éntrega memoria e firme palabra” (1378, Teruel), "sana de mi entendemiento" (1246, Astorga), "en mi buen seso, en mi buena memoria, en mi buena fabla" (ca. 1363, Zaragoza), "en mi buen seso, memoria e entendimiento" (1481, Hita); los fechados entre los siglos XVI y XVII repiten los términos y esquemas anteriores - "en mi buen seso, sana memoria y palavra manifiesta" (1506, Calatayud), "en mi buen seso y recuerdo y manifiesta palabra" (1522, Sarrión), "en mi buen seso, firme memoria e palabra manifiesta" (1529, Zaragoza), "sana de mi juicio y entendimiento natural” (1598, Guadalajara)—; los textos albaceteños fechados entre 1588 y 1600 prefieren combinaciones sobre "en mi (entero) juicio (y entendimiento)"18 o "en mi buen (seso), juicio (y entendimiento) (natural)", y los estudios sobre testamentos murcianos del siglo XVI presentan repetida la fórmula "en mi buen seso e sana e entera memoria” (Díez de Revenga e Igualada, 1997: 41).
Asimismo, todas estas variantes respetan las fórmulas que se transcriben en compilaciones legales y manuales de escribientes: desde la austeridad de la alfonsí "seyendo enfermo del cuerpo et sano de la voluntat" (Partida III, ley CIII) o la ausencia de ornato de González de Carvajal ("estando enfermo, pero en mi seso y juyzio") hasta la amplificación de otras como la de Lorenzo de Niebla: "estando sano y con salud y en mi buen seso y entendimiento, cumplida e buan memoria y perfecto juyzio natural, qual plugo a Dios nuestros señor de me querer dar" (Lorenzo de Niebla, Summa de estilo de escrivanos y de herencias, y particiones y escripturas y avisos de Juezes, apud Mártir, 2011: 218). En cualquier caso, aderezada con más o menos elementos, la fórmula escogida hace uso sin excepción de los términos mencionados anteriormente, que comprenden el seso, entendimiento, memoria, juicio, y voluntad, en menor medida, que serán naturales, buenos, libres, cumplidos y perfectos.

En la muestra navarra del siglo XVIII (Tabernero, en prensa) se hace referencia al entendimiento y a la palabra, el primero cabal y clara y manifiesta la segunda: "estando como estoy bueno y en mi cabal entendimiento y palabra clara y manifiesta", que supone varias modificaciones respecto a las fórmulas de los siglos precedentes. El cambio fundamental no viene representado por la categoría sustantiva, que se conserva, sobre todo en entendimiento antes que en la menos frecuente palabra, sino por los términos adjetivos. La expresión cabal entendimiento se registra en CORDE únicamente a partir de 1589, en la Elegía de varones ilustres de Indias de Juan de Castellanos, donde se constata con reiteración, y posteriormente en los siglos XIX y XX (también en (REA), aunque las ocurrencias son pocas. $\operatorname{Sin}$ embargo, el adjetivo aislado, sin formar parte de

16 El orden verbo + adjetivo (sea o sia manifiesto) resulta más duradero en el tiempo que la fórmula adjetivo+ verbo (manifiesto sea o sia).

17 Los ejemplos que copio a continuación proceden de los textos del CODEA

18 Predomina entre todas las variantes posibles "en mi entero juicio". 
una lexía compleja, se atestigua desde el siglo XIII, según los datos del CORDE, y será con el correr del siglo XVI, y sobre todo del XVII, cuando el término comience a prodigarse por los textos de tipologías muy diversas, aunque en ningún caso jurídica, de donde se reafirma, de un lado, el conservadurismo de este tipo de discurso, que permite las innovaciones léxicas mucho tiempo después de su incorporación a la lengua de otros ámbitos; de otro, la pertenencia de este término a la lengua culta por su presencia en textos de corte literario, ensayístico, historiográfico o doctrinal, lo que facilitaría su entrada en los textos jurídicos.

Por su parte, la palabra se califica de clara - 'evidente, cierta, manifiesta' - y manifiesta - 'descubierta, patente, clara'-. Palabra manifiesta aparece en cinco testamentos zaragozanos del siglo XVI ${ }^{19}$ como parte de una fórmula que se repite de modo idéntico en todos los casos: en mi buen seso, firme memoria e palabra manifiesta, que coincide con los formularios notariales aragoneses de los siglos XV y XVI ${ }^{20}$. Cierto es, por tanto, y de este modo parecen ir corroborándolo los cambios formularios, que el siglo XVIII supone, como se establece de la historia del derecho, un momento nuevo en la redacción de los testamentos, con todas las salvedades con que el término "novedad" haya de ser interpretado al aplicarse al ámbito jurídico.

La declaración de facultades mentales puede completarse con la atribución a Dios de este buen jucio; la fórmula de los documentos navarros del siglo XVII — "qual dios nuestro señor me hizo merced de dar ante todas cossas" (1635) presenta ligeras variaciones sobre las indicadas por los manuales de escribientes coetáneos redactados en Castilla — "tovo por bien de me dar" (Relator), "le plugo me dar”, (Medina), "qual a Dios nuestro señor plugo de me lo dar" (Huerta), "qual plugo a Dios nuestro Señor de me querer dar" (Niebla) - y en Aragón - "por gracia de Nuestro Senyor Dios" (Formulario notarial del Archivo Municipal de Barbastro: 166) o "Dios lohado" (Formulario notarial zaragozano de la primera mitad del siglo XVI: 83) - , que preceden, en el caso de los aragoneses, a la manifestación sobre la salud mental. Las modificaciones observadas agrupan semánticamente, no así desde el punto de vista léxico, los textos navarros y aragoneses, que inciden semasiológicamente en el favor divino a través de sustantivos como merced o gracia ${ }^{21}$; en cambio, los castellanos prefieren insistir en el carácter voluntario de la acción de Dios (plugo, tovo por bien, me querer dar).

De otro lado, el texto navarro del siglo XVIII emplea la fórmula "gracias a su Divina Magestad" (1762), en la que se aprecia una denominación que, según datos del CORDE, por ejemplo, había decaído en uso en esta centuria tras un período de auge que correspondería al siglo XVII. Por otra parte, el análisis de los resultados de este banco de datos indica una tipología textual que no se relaciona únicamente con la lengua jurídica.

\subsubsection{Notificación o preámbulo}

El preámbulo, que coincide con el exordio de la retórica clásica, difiere también entre las muestras de los siglos XVII y XVIII. Las primeras, idénticas en sus términos, continúan la línea de los

19 Los fechados en 1513, 1555 y 1579 aparecen recogidos en el CORDE [27-06-2014] y otros dos de 1526 y 1529 se encuentran entre los editados en el CODEA [27-06-2014]. Estos dos últimos están redactados por diferentes notarios (Lois Sora, de un lado, y Juan Campi, de otro). Puede añadirse aquí el testimonio de la carta testamentaria de Calatayud, de 1506, que supone una ligera modificación sobre la fórmula más general.

20 Figura en ambos la fórmula testamentaria: "en mi buen seso, firme memoria et palavra manifiesta” (Formulario notarial del Archivo Municipal de Barbastro: 166); "en mi buen seso, firme memoria, palabra manifiesta” (Formulario notarial zaragozano de la primera mitad del siglo XVI: 83). Para Navarra, según informa García-Granero (1980) y se ha señalado ya en estas páginas (\$2), no se conoce la existencia de formularios notariales entre los siglos XIII y XVI.

21 Esto es, términos que comparten rasgos semánticos y que entablan, por tanto, relaciones de significado. 
modelos de finales del siglo XIV o principios del $\mathrm{XV}$, que contienen una breve exposición de motivos - la conciencia de la muerte, principalmente, junto a la "paz y concierto" de los herederos-; figura también la encomendación religiosa, pero no así la protestación de fe, que comenzará a aparecer en los testamentos a partir de mitades del siglo XV (Mártir, 2011: 219)22. Los documentos navarros y aragoneses de estos siglos difieren en este punto de los propios de otras zonas, de tradición castellana, de acuerdo con lo que dejan ver los respectivos formularios: Ios castellanos incluyen en su mayoría este elemento, frente a los aragoneses, que se muestran más escuetos en su redacción, aunque bien es cierto que el mayor o menor ornato de esta dependía, como se ha señalado en varias ocasiones, de la relevancia social del testador y, por ende, de la retribución recibida por el escribano (Mártir, 2011: 219).

Más prolijos, sin embargo, se presentan en este sentido los testamentos del siglo XVIII, al menos los consultados en este trabajo, tanto el localizado en Navarra como los malagueños estudiados por M. Reder (1986) o el bilbaíno editado por J. L. Ramírez Luengo y S. Gómez Seibane (2007: 111), si bien se constatan entre ellos diferencias de grado en el número de elementos posibles que puede integrar este preámbulo —culpa, proximidad de la muerte, protestación de fe e intercesiones-y la extensión dedicada a cada uno de ellos, que se gradúa de menor a mayor desde el testamento de una viuda de Bilbao, pasando por los malagueños, hasta el navarro redactado por un escribano real (Villava, 1762), cuya retórica abunda en superlativos y polinomios léxicos; a su lado perduran en este último documento las fórmulas presentes en los testamentos de la centuria anterior y, paradójicamente, la religiosidad se acusa con mayor vehemencia incluso en el siglo XVIII, al cambiar "desseando con toda my voluntad" por "deseando como catolico cristiano" e insistir en la culpa y el arrepentimiento ("que por mi culpa no he cumplido como debia"); aumentan asimismo los polinomios léxicos en el número de elementos de unos textos a otro (de "restitucion y satisfacion de los cargos" a "restitucion y satisfacion y paga de los cargos"). Algunos de estos rasgos, como la mencionada presencia de la motivación religiosa, que implica el reconocimiento explícito de la culpa, o la amplificación léxica, aparecen ya recogidos en los formularios del siglo XVI; el documento navarro del setecientos recoge incluso la alusión excepcional a cuestiones materiales ${ }^{23}$. Por su parte, la protestación de fe, la invocación y las intercesiones se revisten igualmente en el texto citado del carácter ampuloso que acompaña a toda esta parte ${ }^{24}$.

El único aspecto que establece diferencias geográficas entre los documentos afecta al léxico de la fórmula de revocación empleada, que, de acuerdo con las indicaciones de los manuales aragoneses al uso (Formulario: 166 y Formulario: 83), perpetúa en la Edad Moderna los términos jurídicos medievales casar y relicar, especialmente arraigados en Aragón y Navarra (Tabernero, 2012: 534, y en prensa ${ }^{25}$. En otras sintopías, como la albaceteña (García Moratalla, 1999), predomina la utilización de revocar, usado igualmente en el resto de localizaciones, pero sin la yuxtaposición o coordinación de otros verbos.

Por otra parte, en la misma línea de uso retórico que ya se ha señalado para el documento navarro del siglo XVIII, también en esta ocasión

22 Por ejemplo, se comprueba el seguimiento de estos modelos en los testamentos albaceteños del siglo XVI editados por García Moratalla (1999).

23 Entre los formularios que estudia M. J. Mártir (2011: 219) solo uno de ellos, el de Valdepeñas, introduce la referencia a los bienes materiales.

24 Entre los formularios castellanos del siglo XVI, Roque de Huerta ofrece una "cabeza de testamento" amplia y otra más breve; aunque difieran en la forma, en la primera "cabeza" se aprecia el mismo tono recargado de este texto nuestro del XVIII (Huerta, 1551: 22-24).

25 El testamento navarro de 1762 emplea ya únicamente anular y revocar: "rebocando y anulando todos y cuales quier testamento, ó testamentos, cobdecillo, o, cobdecillos, que hantes de este testamento, se hallaren hechos, o, mandados hacer, asi por escrito como de palabra (1762). 
se abunda en el hecho de la invalidación: "que no quiero ni consiento que balga ninguno de ellos nin haga fe, en juicio, ni fuera de el, si no este que al presente hago y ordeno" (Villava, 1762).

Según los documentos consultados de diferentes localizaciones y cronologías, no existe solución de continuidad en las fórmulas empleadas desde la Edad Media hasta el siglo XVIII para dar paso a las cláusulas dispositivas²6. "(H)ago y ordeno" se presenta como la fórmula más extendida, que se incluye, con ligeras variantes, en la mayoría de los textos consultados. En ocasiones, sin que se produzcan alteraciones en las lexías propiamente dichas ("hago y ordeno", "forma y manera siguiente”), pueden variar la disposición y el espacio concedido a cada una de las partes, como sucede en el testamento de Villava de 1762, de modo que la introducción de las disposiciones, casi idéntica a otras épocas y dataciones ("Por lo cual27 imbocando la gracia del espiritu Santo, hago y ordeno"), se incluye en el préambulo y queda interrumpida por la profesión de fe, las peticiones de intercesión a la Santísima Trinidad, a la Virgen María y a un largo etcétera de ángeles y santos y por la revocación de otros testamentos, reanudándose posteriormente con la presencia otra vez de los binomios léxicos "hago y ordeno" y "quiero y es mi voluntad", que marcan la vuelta a la introducción de las mandas, que añade elementos de especificidad a este texto en concreto.

\subsection{Cuerpo del testamento: cláusulas dispositivas}

La parte nuclear del testamento comprende las cláusulas de disposición de sepultura y funeral, los legados o mandas, el nombramiento de albacea, la institución de heredero, eventualmente las sustituciones de herederos al igual que las cláusulas de desheredación y la de tutela, la cláusula de revocación y la codicilar, que se suceden teóricamente siguiendo el orden expuesto (Mártir, 2011: 224).

Siendo esta una de las posibilidades de estructuración, en varios de los documentos estudiados se advierte, sin embargo, una ligera alteración del orden propuesto que afecta a la cláusula de revocación y la codicilar, incluida en estos casos en la cabeza del testamento, y al nombramiento de albacea o cabezalero, cierre de las cláusulas dispositivas.

La previsión de sepultura y honras funerarias, a la que acompañan la encomendación y súplica de perdón, abre las cláusulas dispositivas en los textos de todas las épocas estudiadas: en los anteriores a 1700 de diversas procedencias (CODEA), en los albaceteños del siglo XVI (García Moratalla, 2011), en los de Bilbao y Málaga del siglo XVIII, coincidiendo con las indicaciones de los formularios de la centuria del quinientos (Mártir, 2011). Presentan casi todos ellos la misma fórmula con ligeras modificaciones, que encabeza de manera unánime el adverbio primeramente ${ }^{28}$. "Primeramente encomiendo my anima a dios nuestro señor que la crio y a la gloriossa”. En los textos medievales y en los pertenecientes a la Edad Moderna, sobre todo de Navarra y Aragón, se establece únicamente la cláusula de encomendación de alma, de acuerdo con los formularios aragoneses, mientras que los propios de los siglos XVI y XVII de Guadalajara, 1598, o Albacete, 1594, se amplía también al cuerpo29, según consta en los formularios castellanos.

26 En su estudio sobre los formularios castellanos del siglo XVI, señala M. J. Mártir (2011: 224) cómo "las fórmulas que introducen el dispositivo son muy parecidas entre sí, apreciándose dos grupos según los verbos empleados, 〈hago y ordeno〉 que aparecen en el Relator, en la más extendida de Valdepeñas, en Huerta, Niebla y Torneo; mientras Ribera se limita a 〈ordenos y Medina, Valdepeñas, Monterroso y Carvajal emplean cotorgo y conozco que〉, 〈hago establezco u ordenos, no apreciándose ninguna diferencia en su empleo entre inicio y fin de siglo".

27 Se observa el cambio - esperable-del marcador por lo cual en lugar del por ende de la centuria anterior.

28 Claro está con los cambios gráficos y fonéticos propios de cada época.

29 Pertenecen al documento 0195 del CODEA [consulta 06-06-2014] y al documento 23 que edita García Moratalla (1999, 143), respectivamente. 
Por su parte, los textos del siglo XVIII alternan la forma de encabezamiento primeramente - texto de Bilbao y navarro- con lo primero - testamentos de Málaga - y continúan el uso de la primera cláusula para el señalamiento de sepultura y funerales.

De acuerdo con la descripción de M. J. Heredia (2002: 168) para los testamentos áureos, "Ios bienes donados se separan puntualmente y el detalle de cada uno de los asuntos del testamento queda recogido por partes. Como regla general, se comienza por "solucionar" lo asuntos espirituales que preocupan al testador para, seguidamente, pasar a los bienes materiales. Para lo primero se especifican y detallan tanto las condiciones de enterramiento como las donaciones y limosnas para misas".

El marcador item ${ }^{30}$ servirá de introductor a las distintas disposiciones de forma generalizada a lo largo de los siglos, si bien la documentación murciana parece preferir el romance otrosí (Díez de Revenga e Igualada, 1997: 46; Heredia, 2003: 169). Por su parte, el carácter impositivo de la fórmula escogida para abrir estas disposiciones se va acentuando con el tiempo: las medievales y clásicas "fago e ordeno", "otorgo e ordeno" - "fago e ordeno mío testamento" (CORDE, León, 1309), "fazemos e ordenamos" (CODEA, Teruel, 1522) - , que inciden en el testamento como acción, alternan en las mismas épocas con la marcación de la voluntad — "quiero et atorgo", "quiero e mando" (CODEA, Teruel, 1378) - hasta llegar desde la documentación notarial desde el siglo XV (CORDE) al doblemente imperativo "ordeno y mando", que se ofrece como una de las posibilidades al lado del simple "mando" albaceteño (García Moratalla, 2010) o del trinomio "quiero, ordeno y mando" de los formularios aragoneses (Formulario notarial del Archivo Municipal de
Barbastro: 166). En ocasiones, sin embargo, ambos actos -imperativo y volitivo - se combinan en cualquiera de las épocas y geografías estudiadas, mediante la acumulación de fórmulas; de este modo se lee "quiero y es mi voluntad" como variación de las combinaciones anteriores, en aposición al mencionado "ordeno y mando".

En el cuerpo de los testamentos se respeta en cada una de las mandas el carácter formulario, principalmente a través del uso de lexías complejas, que se presentarán en mayor o menor grado según causas ajenas en principio a factores cronológicos o geográficos. En efecto, los binomios o polinomios sinonímicos pertenecen a la lengua jurídica desde la época medieval y llegan, al menos, hasta el límite cronológico que abarca este trabajo: (fuero), uso y costumbre, hauer y heredar, dejado y mandado, honrras y funerarias, yntençion y voluntad, subcesion y herencia, ofrecidas y gastadas, pedidas y cobradas, poder y facultad, Ilamados y rogados, fe y credito, satisfacer y pagar, bean y registren, ruego y suplico, pagamentos y restituciones, cumplido y pagado, vltimo testamento y determinada voluntad, drechos y acciones, tocary pertenecer, subcesion y herencia, clausula y tenor, dispuesto y ordenado, herederos y subcesores.

Con todo, no dejan de apreciarse a este respecto cambios en estas lexías o unidades léxicas provocados por el paso del tiempo, que favorece el empleo de términos nuevos en la lengua jurídica del XVIII, como el verbo estilar(se) en "se estila ${ }^{31}$ y practica" (Villava, 1762) como sustituto del "uso y costumbre" o "se acostumbra" anteriores; también el uso jurídico propicia la consolidación de acepciones nuevas tal como sucede en "esfera, estado y calidad", donde esfera, término especialmente usado en la lengua poética del siglo XVII, muestra un sentido metafórico que parece ser común desde la centuria siguiente (CORDE).

30 También se emplea item de modo general en los testamentos altoaragoneses del siglo XVII transcritos por N. Rapún (2001-2002).

31 Corominas (DCECH, s. v. estilo) ofrece a Covarrubias como primera documentación del verbo estilar; por su parte, la búsqueda en el CORDE [consulta 19-08-2014] apunta hacia un empleo mayoritario a partir del siglo XVIII, aunque, claro está, las dataciones primeras sean anteriores. 
En esta parte, el documento navarro del siglo XVIII, al que se han hecho repetidas referencias, se muestra igualmente específico en las disposiciones, que participan del estilo amplificado que se ha señalado en el caso del exordio (\$3.1.3), cuyo elemento más significativo consiste en la acumulación de binomios y polinomios léxicos. De hecho, esta superabundancia formularia no resulta comparable a los otros testamentos coetáneos analizados, que se muestran conformes con los usos de épocas precedentes. Por esta razón, según creo, son motivos de índole social los que provocan la ampulosidad de la redacción, que puede relacionarse con la condición de escribano real del testador. Este, conocedor de la literatura testamentaria, mandaría al redactor a aplicar todos los elementos posibles para la elevación del texto, evidenciando de esta manera el valor del documento como liberador del alma y manifiesto de su honda religiosidad.

Asimismo, es en el cuerpo del documento, allí donde las cláusulas contienen una redacción menos formularia, el momento en que se registran algunos términos locales, que, como es sabido, irán decreciendo paulatinamente a medida que pasen los siglos y la lengua española se configure como una realidad cada vez más homogénea, que se resuelve geográficamente marcada en las denominaciones más cotidianas (Tabernero, 2012).

\subsection{Protocolo final: data tópica, crono- lógica y validación}

Como parte última de los testamentos, los protocolos finales contienen, sin apenas renovaciones formularias de un siglo a otro, la data tópica y cronológica, la nómina de los testigos y la validación del documento por parte del escribano, que da fe y testimonio de todo lo contenido en la escritura pública y lo hace en primera persona. Esta formulación deja patente la importancia nuclear del escribano por encima de los testigos, a pesar del papel principal que las Partidas, por influencia del derecho romano, atribuían a estos. Es cierto, sin embargo, como señala M. J. Mártir (2011: 309), que las indicaciones del código legal alfonsí no se aplicarán a este respecto, pues el escribano seguirá siendo el eje central en la redacción de este tipo de discursos (Mártir, 2011: 309).

En la mayoría de los textos consultados, los testigos se enuncian con la fórmula "Ilamados y rogados", que, según dejan ver los formularios castellanos del XVI, supone un alargamiento frente al "llamados" único de épocas anteriores ${ }^{32}$.

En cuanto a la validación del notario, los testamentos examinados del siglo XVIII conocen todavía la fórmula "doy fe e conozco"33, que representó en las centurias precedentes ${ }^{34}$, incluidas las medievales, el modo de expresión más común; junto a ella aparece la lexía "doy fe y verdadero testimonio", presente en el testamento navarro de 1762, que debía estar consolidada como marca de autenticación documental ya en el siglo XVII35.

Ha de notarse, sin embargo, en los testamentos del siglo XVIII que hemos consultado, la reducción que sufre la parte destinada a la fe del notario, que incluso desaparece, como sucede en el documento de Bilbao o en alguno de los testamentos malagueños. Este hecho, que coincide con la simplificación que se ha hecho notar en la clasificación cronológica de J. Bono y Huerta (1980), no se aplica, en cambio, a la muestra navarra de esta centuria.

32 Así lo hace notar M. J. Mártir (2011: 311) de acuerdo con los datos obtenidos de los formularios castellanos, que incluyen "rogados" a partir de 1534.

33 Es esta la expresión que se emplea, por ejemplo, en los testamentos del siglo XVIII transcritos por M. Reder (1986).

34 Así, por ejemplo, en los documentos del XVI y XVII que han servido como base de comparación de nuestro estudio.

35 Los testimonios que ofrece CORDE para esta fórmula se reparten equitativamente, sin que se puedan considerar significativas las diferencias numéricas observadas entre los siglos XVI y XVIII, con un primer testimonio de 1516 y un último de 1781, momento a partir del cual desaparece, al menos de los textos contemplados en el banco de datos académico. 


\section{Variación en el discurso testamentario}

Según se ha podido comprobar en los epígrafes precedentes, sobre el respeto a la estructura tradicional de la Edad Media (\$3), el discurso testamentario refleja, incluso en sus elementos más formularios, aspectos de variación diacrónica y geográfica.

Aunque anunciada de modo progresivo en los siglos precedentes, se muestra claramente la frontera divisoria que separa la centuria del XVIII de las anteriores, tanto en las modificaciones propiamente diplomáticas de estructura del documento, como en aquellas referidas al cambio en el uso de las fórmulas, que dan noticia de la evolución en el léxico. El preámbulo (\$3.1.3) y el cuerpo del testamento (\$3.2) resultan las partes más susceptibles de alteración sobre los modelos anteriores, que se distinguen, asimismo, en función de la datación tópica, que agrupa, de un lado, Aragón y Navarra, y Castilla, de otro. Esta reunión de sintopías se repite en las diferencias en la cláusula de encomendación del cuerpo del testamento (\$3.2). Por su parte, la fe del notario se ve reducida a partir de los testimonios del setecientos (\$3.3).

Más significativas desde ambos puntos de vista - diatópico y diacrónico - resultan las modificaciones en las fórmulas, que recorren cada una de las partes de la carta testamentaria. Desde el "sepan" de raigambre medieval hasta la consolidación en el XVIII del "notorio y manifiesto sea” de la invocación (\$3.1.1); desde la "memoria" de los siglos XII-XV, pasando por el "juicio" del quinientos y del seiscientos, hasta lo "cabal" del entendimiento y lo "claro" de la palabra en la intitulación del setecientos (\$3.1.2); o del "hago y ordeno" primero al "ordeno y mando" dieciochesco en la introducción a las cláusulas dispositivas (\$3.1.3), además de la entrada de elementos léxicos nuevos o arraigados a partir de 1700 (estilarse) o la sustitución de otros anteriores (acostumbrar) (\$3.2) o el uso de marcadores de inicio o suma diferentes de los habituales hasta entonces (primeramente, lo primero, item, otrosi) (\$3.2).
Por su parte, los usos formularios difieren en ocasiones entre Aragón, al que se añade Navarra y Castilla, incluso en aquellos siglos en que la división dialectal histórica pertenece ya a épocas pasadas. Algunas de estas divergencias encuentran efectivamente su explicación en la pervivencia de peculiaridades diatópicas (relicando, casando) (\$3.1.3); en cambio, otras ('favor'/'volición’) se deben a la tradición manifestada en los manuales de escribientes o en los formularios notariales que proliferaron a partir del siglo XVI (\$3.1.2).

En definitiva, el testamento se presenta como discurso privado que limita con lo público ("Sepan quantos esta presente carta de testamento vieren u oyeren", "Notorio y manifiesto sea a todos los que leyeren y oyeren el presente instrumento"), pues nace para ser leído ante un colectivo restringido, aquel que pertenece al entorno del testador, y en unas condiciones de enunciación que participan de los dos ámbitos, público y privado: quien escribe no es el testador, sino el escribano, que filtra de algún modo la voluntad de aquel; para validar el testamento, este debe realizarse en presencia de testigos y el emisor está investido de autoridad sobre sus destinatarios, que se ven impelidos al cumplimiento de lo testado; este poder establece cierta distancia con sus interlocutores, a los que se dirige en tercera persona, reforzando de este modo el carácter imperativo. No es necesario convencer a los herederos sobre la validez de hechos o acciones, ya que el testador hace uso de su superioridad respecto a ellos, lo que no sirve, en cambio, en la relación con Aquel que ordena el fin último, la salvación del alma.

Por tanto, desde la Edad Media hasta el siglo XVIII la finalidad del testamento consistía en ganar el cielo y disfrutar el poder que concede la posesión de los bienes terrenales, de modo que el discurso había de articularse alrededor de estos dos elementos. De una parte, la exhibición del sentimiento religioso — profesión de fe, intercesiones y encomendaciones - y las mandas pías y forzosas asegurarán la salvación del alma $y$, de otra, el reparto de los bienes entre los he- 
rederos y la designación del heredero universal impondrán la voluntad del testador, que se presenta como un intercambio por el cumplimiento de determinadas obligaciones (sepultura y honras fúnebres), expresadas lingüísticamente de forma impositiva ("hago y ordeno", "quiero et es mi voluntad", "ordeno y mando").

El testamento se establece, por tanto, como género discursivo de características propias, que, al lado de elementos de la retórica clásica, atiende a las necesidades establecidas por el discurso jurídico y todo ello en el contexto de unos siglos en que la religión, como camino de salvación, constituía el eje ideológico y social. De esta manera, en una estructura tripartita, que recuerda los principios retóricos, se comprueba la presencia de elementos que tienen que ver con la naturaleza jurídica y religiosa del acto de testar (invocación, intitulación y protocolo final) junto a otros comunes al discurso en general, el preámbulo o exordio y, en cierto modo, las cláusulas dispositivas, como parte central, que en ocasiones contiene incluso la argumentación o justificación de lo establecido ("dejo a Ana Francisca de Yrisarri [..] la casaca de paño [...] para que se acuerde de encomendar mi alma y rogar á Nuestro Señor por la salbacion de ella”, [Villava, 1762]).

Como se ha dicho más arriba, la macroestructura discursiva del testamento respeta, a lo largo de las centurias estudiadas, la tradición medieval; no así la microestructura en la que se descubren variaciones que trasladan de lugar elementos como la revocación y que han de explicarse igualmente por la continuidad de los modelos y tradiciones que se establecen en los manuales de escribientes, entre los cuales escoge el redactor del texto. Asimismo, las fórmulas, intrínsecamente resistentes al cambio o a la sustitución de alguno de sus elementos, dejan apreciar la evolución que se produce a lo largo de las diferentes centurias, si bien con retraso evidente sobre la lengua común. De igual forma, también la cronología, de acuerdo con el proceso de nivelación del español, irá despojando estos textos de los dialectalismos imperantes en épocas anteriores. Puede afirmarse, por tanto, que en la delimitación del testamento como tradición discursiva resultan significativos la cronología, el emisor ${ }^{36}$, y la variación diatópica, que permite modificaciones en sus elementos formularios.

En este sentido merece especial atención el documento navarro de 1762, de cuya particularidad y llamativa ampulosidad se ha dado noticia repetida a lo largo de este estudio. Precisamente, la intensificación de recursos que presenta la redacción de este documento contraviene la afirmación jurídica sobre la progresiva simplificación y racionalización de la literatura notarial del siglo XVIII, lo que representa, antes que una constatación contraria a la comúnmente admitida, la especial relevancia de determinados elementos en la historia de una tradición discursiva. En este caso se pone de manifiesto la importancia de la condición social del testador, vinculada aquí a la profesión de escribano, que conoce todas las estrategias que le ofrece el discurso para conseguir el fin último que da sentido al acto de testar, esto es, la salvación de su alma. Es cierto, sin embargo, que el barroquismo, como lo ha denominado J. Bono y Huerta, de los testamentos del XVII y la profunda religiosidad se muestran en esta ocasión de forma tan evidente que es difícil dejar de pensar, por un lado, en un apego a la tradición, mayor en unas zonas que otras, y, por otro lado, como causa última en la persistencia, también en unos lugares más que en otros, de la religiosidad propia de otros momentos, sin que se haya producido todavía la racionalización que conducirá hacia la forma de los testamentos actuales. Encontramos el refrendo a esta afirmación en el

36 Navarro (2012 y 2015) muestra, asimismo, la influencia del testador y especialmente del escribano como elementos de variación del testamento. 
uso de expresiones del ámbito de la religión que se encontraban ya en claro retroceso - "Divina Magestad" - tras el auge experimentado en el siglo precedente (\$3.1.2).

\section{Bibliografía citada}

Benavides, Irene Victoria, 2000: "Algunas fórmulas de contenido religioso en el protocolo de documentación asturleonesa (775-1230)", AnMal electrónica 6 [disponible en http://www.anmal.uma. es/numero6/Benavides.htm, fecha de consulta 20 de noviembre de 2014].

Bono y Huerta, José, 1980: "Los formularios españoles de los siglos XVI, XVII y XVIII", Anales de la Academia Matritense del Notariado 22, 1, 287-318.

Campo, Ana del, 2011: El Libro de Testamentos de 1384-1407 del notario Vicente de Rodilla. Una introducción a los documentos medievales de últimas voluntades de Zaragoza, Zaragoza: Institución Fernando el Católico.

Chiffoleau, Jacques, 2011 [1980]: La comptabilité de l'Au-Delà : les hommes, la mort et la religion dans la région d’Avignon à la fin du Moyen Âge (vers 1320-vers 1480), Paris: Albin Michel.

Codoñer, Carmen, 1972: "Léxico de las fórmulas de donación del siglo X”, Emérita: Revista de lingüística y filología clásica 40, 141-149.

Corde: Real Academia Española: Corpus diacrónico del español (Corde) [disponible en http://www.rae. es, fecha de consulta 21 de diciembre de 2014].

CoRIA, Jesús, 1982: "El testamento como fuente de estudio sobre mentalidades (s. XIII al XV)", Miscelánea Medieval Murciana 9, 193-219.

Diez de Revenga, Pilar y Dolores Igualada, 1997: “La lengua de los testamentos (siglos XV y XVI)", Revista de Investigación Lingüística 1, 37-58.
Formulario notarial del Archivo Municipal de Barbastro, 2001: introducción, transcripción y notas por José Ángel Sesma Muñoz con la colaboración de Ma Teresa Sauco Álvarez y Susana Lozano Gracia, Zaragoza: El Justicia de Aragón.

Formulario notarial zaragozano de la primera mitad del siglo XVI, 2001: transcripción y notas por Cristina Monterde Albiac y María Rosa Gutiérrez Iglesias, Zaragoza: El Justicia de Aragón.

García-Granero, Juan, 1980: "Formularios notariales de los siglos XIII al XVI", Anales de la Academia Matritense del Notariado 22, 1, 227-286.

García Moratalla, Pedro Joaquín, 1999: Los testamentos en Albacete a finales del siglo XVI (15881600). Modelo informativo de las fuentes notariales, Albacete: Instituto de Estudios Albacetenses "Don Juan Manuel".

Githe (Grupo de Investigación de Textos para la Historia del Español): Banco de datos (Codea) [en línea]. Corpus de Documentos Españoles Anteriores a 1700 [disponible en http://demos.bitext. com/codea/codea_form.asp, fecha de consulta 21 de junio de 2013].

Gómez Selbane, Sara y José Luis Ramírez Luengo, 2007: El castellano de Bilbao en el siglo XVIII. Materiales para su estudio, Bilbao: Universidad de Deusto.

Heredia, M. José, 2003: “Los testamentos. Un tipo textual con tradición: de la Edad Media a la actualidad”, Revista de investigación lingüística 5, 155-178.

Huerta, Roque de, 1551: Recopilación de notas de escripturas pvblicas, vtiles y muy prouechosas, Salamanca: Juan de Junta.

LAFFon, Luisa, 1989: "Arenga hispana: una aproximación a los preámbulos documentales de la Edad Media", Historia, instituciones, documentos 16, $133-232$. 
LALINDE, Jesús, 1998 [1970]: Iniciación histórica al Derecho español, Barcelona: EUB.

LoRenzo, Francisco Javier, 1989: Actitudes religiosas ante la muerte en Zamora en el siglo XVI: un estudio de mentalidades, Zamora: Instituto de estudios zamoranos.

Martínez GIL, Fernando, 1993: Muerte y sociedad en la España de los Austrias, Madrid: Universidad Castilla - La Mancha.

MÁrtir, M. José, 2011: Los testamentos en los formularios castellanos del siglo XVI, Servicio de Publicaciones: Universidad de Granada.

Medina, Juan de, 1539: Suma de notas copiosas muy sustanciales y compendiosas segun el vso y estilo que agora se vsa enesttos reynos.

Medina, Javier, 1997: "El español de Canarias a través de la documentación testamentaria (siglos XVI-XVIII)", Boletín de Filología 36, 163-189.

Navarro, Rosario, 2012: "Registro, variación lingüistica y contacto de lenguas en un tipo textual: la carta de testamento", Revista Internacional de Lingüística Iberoamericana 20/2, 127-147.

NavarRo, Rosario, 2015: "La carta de testamento: un tipo textual" en El libro de protocolo del primer notario indígena (Cuzco, siglo XVI). Cuestiones filológicas, discurisvas y de contacto de lenguas, Madrid-Frankfurt: Iberoamericana-Vervuert, 87-165.

Peñafiel, Antonio, 1987: Testamento y buena muerte (Un estudio de mentalidades en la Murcia del siglo XVIII), Murcia: Academia Alfonso X el Sabio.

Pons, Lola, 2008: "El peso de la tradición discursiva en un proceso de textualización: un ejemplo en la Edad Media castellana" en Johannes Kabatek (ed.): Sintaxis histórica del español y cambio lingüístico: nuevas perspectivas de las Tradiciones Discursivas, Madrid - Frankfurt am Main: Iberoamericana-Vervuert, 197-224.
Rapún, Natividad, 2001-2002: “Transcripción de testamentos unipersonales del siglo XVII en el medio rural del Alto Aragón”, Revista de Derecho civil aragonés 7-8, 269-310 [disponible en http:// goo.gl/BSDj7n, fecha de consulta 10 de noviembre de 2014].

Reder, Marion, 1986: Morir en Málaga. Testamentos malagueños del siglo XVIII, Málaga: Universidad de Málaga / Diputación Provincial de Málaga.

Retamal, Julio, 2000: Testamentos de indios en Chile colonial: 1564-1801, Santiago de Chile: Universidad de Andrés Bello.

Rodrigo, María Luz, 2002: Testamentos medievales aragoneses. Ritos y actitudes ante la muerte (sig/o XV), Zaragoza: Ediciones 94.

SAInz, Loisi, 2011: "Estudio lingüístico de testamentos escritos en Cuba en los siglos XVI, XVII y XVIII. Estructura sintáctica de la voz pasiva”, Signos lingüísticos 7/14, 115-139.

Tabernero, Cristina, 2012: "Documentación jurídica y variación léxica en los siglos XVI y XVII" en C. Martínez Pasamar y C. Tabernero (eds.): "Por seso e por maestría”. Homenaje a la profesora Carmen Saralegui, Pamplona: EUNSA, 523-554.

TABERnERo, Cristina, en prensa: "Usos lingüísticos y discursivos de un documento testamentario del siglo XVIII".

Testamentos coloniales chilenos, 2005: Raïssa Kordic (prólogo y ed. crítica) y Cedomil Goić (estudio preliminar), Pamplona - Madrid - Frankfurt am Main: Universidad de Navarra - Iberoamericana-Vervuert. 